\title{
A Closer Look at Reading Strategy Use in Reading Section of TOEFL iBT
}

\author{
Sayyed Mohammad Alavi \\ Faculty of Foreign Languages and Literatures, University of Tehran, Iran \\ Email: mohammed.alavi@gmail.com \\ Soodeh Bordbar \\ Faculty of Foreign Languages and Literatures, University of Tehran, Iran \\ Email: bluesky7257@yahoo.com
}

\begin{abstract}
This paper investigates any difference in employing Reading strategies, relates them to various item types of reading comprehension in TOEFL iBT (copyrighted by ETS, 2005). Sixty-six respondents (26 males and 40 females) participated in the present study. A list of reading strategies (adopted from Cohen \& Upton, 2006), followed by a test of reading comprehension that took forty-five minutes to complete were used. Before the test begun, the participants were instructed how to specify the strategies that they employed during taking the test. To address the research question, the analyses of the results revealed that the difference is significant in the use of Reading strategies for various item types. On the basis of the findings language teachers are recommended to teach different Reading strategies in order to help TOEFL applicants to use them related to different item types more efficiently and effectively.
\end{abstract}

Index Terms - test-taking strategies, reading strategies, TOEFL iBT, item types of reading section

\section{INTRODUCTION}

One common way of documenting the language ability of post grade students is presenting a score in an internationally known test such as Test of English as a Foreign Language (TOEFL), International English Language Testing System (IELTS), Grade Recode Exam (GRE), etc. Since the 1990s, along with the increasing use of computer technology in language education and the rise in the accessibility of personal computers, making use of computer technology in development of language tests, the delivery and administration have been the focus of researchers. The evolutions in multimedia and web technologies suggest a good number of possibilities for designing and developing computer-based tests that are supposed to be more authentic and interactional than their paper and pencil counterparts (Bachman, 2000). As a tangible result of this evolutional process in late 2005, Internet-Based Test (iBT) was introduced to the language education contents in general, and testing centers in particular. It seems that the iBT being progressively replaced both Computer-based (CBT) and Paper-based (PBT) tests, although paper-based testing is still used in many areas around the world. Test takers often participate in test preparation courses they are going to do. One of the most common instructions in such courses is making the test takers familiar with strategies that proved to be effective in doing various types of tests such as vocabulary, grammar, and reading comprehension. A good number of studies explored the role of test takers' familiarity with test taking strategies in doing TOEFL (Nevo, 1989; Phakiti, 2003a). Very few studies have examined using Reading strategies in doing iBT. It seems that using Reading strategies in performance on iBT test in general, and in doing iBT reading comprehension test in particular, needs more investigation.

\section{LITERATURE REVIEW}

\section{A. Previous Research on Strategy Use}

The recent focus on different strategies in language education appears to change approaches to the teaching and learning process. The test-taking strategies have been referred to as "techniques, tactics, potentially conscious plans, consciously employed operations, learning skills, basic skills, functional skills, cognitive ability, language processing strategies, and problem-solving procedure" (Wenden, 1987, p. 7). Nitko (1983, p. 326) defines test-taking strategy as "a student's ability to use the characteristics of both the test and the test situation to attain a higher score".

Some strategies such as problem solving, grouping, matching, and etc. are common in everyday life. McDonough (1999) argues that strategies that have been used by learners sometimes are not directly related to language learning but are characteristic features of the human brain.

Early references to strategic competence as a part of communicative language use (Canale \& Swain, 1980) emphasize on "compensatory" strategies - which are defined as strategies used to compensate or remediate lacks in some areas. Language use strategies have been defined as the mental actions or processes, which learners consciously select when completing language tasks. These strategies also include test-taking strategies when they are applied to 
tasks in language tests. Test-taking strategies according to Cohen (1994, p. 92) are "test-taking processes that the respondents have selected and of which they are conscious, at least to some degree". In other words, the notion of strategy implies an element of selection. Otherwise, the processes would not be considered strategies.

Having believed that strategies vary according to context, Cohen (1994, p. 92) believes that:

One strategy is to opt out of the language task at hand (e.g., through a surface matching of identical information in the passage and in one of the response choices). Another is to use shortcuts to arrive at answers (e.g., not reading the text as instructed but simply looking immediately for the answers to the given reading comprehension questions). In such cases, the respondents may be using test-wiseness to circumvent the need to tap their actual language knowledge or lack of it.

In a study on multiple-choice reading tests, McDonough (1995) examined a number of strategies which let the reader come to the right answer without actually knowing it from internal linguistic evidence. He found that the students would be allowed to get the right answer for the wrong reasons. As a matter of fact, "the surface matching of test item stem and reading passage, or clues even in the stem itself which matched with one of the options" (McDonough, 1995, p. 109).

\section{B. Previous Research on Strategy Use and Reading Comprehension}

Reading, from cognitive perspective, has been defined as a conversation between author and reader with the construction of meaning from written or printed text. Zhi-hong (2007) states that "there are many factors influencing reading comprehension such as reader's characteristics, nature of reading materials, and reading tasks, etc". Tyner (2004) indicates that "Early reading success...is the cornerstone upon which knowledge, self-esteem, and future educational opportunities are built" (Tyner, 2004, p. 1). "Reading is fundamental to success in life. [It] opens the door to virtually all other learning" (Zimmermann, 2004, p. 4). Reading is defined as "a complex process that brings together a reader and a text. It allows the reader to bring together many strategies to aid in competency" (Fountas \& Pinnell, 1999, p. 4). Reading is an unobservable mental behavior and generally regarded as inaccessible sources of data to researchers. Namely, reading research is classified into two categories process-oriented and product-oriented. Recent research in reading comprehension has focused on the process of reading which is defined as examining the psycholinguistic process.

Alderson (2000) believes that reading is, first and foremost, a purposeful activity. The purpose for reading influences the reader's type of involvement with the text. However, several elements can be considered for succeeding the reading process at any purpose of reading. Some other researchers such as Rumelhart (1980), Stanovich (1980), Anderson and Pearson (1984), Carrell (1984), Aebersold and Field (1997) have discussed that the integrated comprehension of a text relied on the "fluid, accurate, and efficient application of bottom-up processes (Rupp, Ferne, \& Choi, 2006, p. 444).

Nunan (1999) makes distinction between receptive (reading and listening) and productive (writing and speaking) skills. Receptive skills, as essential skills, are considered the only way to receive the knowledge of one language and shape the required competence. A pertinent point to note that speaking and writing depend upon reading and listening. In this regard having written and spoken forms of language associate with only and only have any competence of reading or listening.

During the last 70 years, there have been growing bodies of research on standardized reading tests to measure comprehension (Segel, 1986). Cohen (1980) states that different methods and techniques such as open-ended questions, cloze, true/false, sentence completion, summary and multiple- choice can be used to assess reading comprehension. Very common of these methods is multiple-choice format in standardized reading tests. This format has also been mostly criticized, because the respondents reach the correct answers more than one way and can be recognizable "without actually understanding the text and without any judgmental activity in selecting the correct response" (KleinBraley, as cited in Nevo, 1989, p. 201).

Having reviewed the research on the use of problem-solving strategies in the test, Messick (1989, p. 54) states that" different individuals performed the same task in different ways and ... the same individual might perform in a different manner across items or on different occasions". It is important to recognize that strategies and a group of skills can be used to facilitate test of reading comprehension. A distinction was made between reading strategies and reading skills, because there was a great deal of overlap in what was called reading skill and reading strategies (e.g. Wenden \& Rubin, 1987; Alderson, 2000; Grabe, 2000).

Rupp et al. (2006, p. 447) defined skills as "typically considered to be automatic internalized reading abilities possessed by learners, which consciously facilitated their reading comprehension in both non-testing situations", by contrast strategies referred to "conscious techniques and tactics deliberately employed by a reader for successful reading such as the use of a dictionary, the underlining of key words, or the skimming and scanning of certain sections" (e.g. Clarke, 1979; Barnett, 1989; Anderson, et al., 1991; Aebersold \& Field, 1997; Alderson, 2000; Birch, 2002; Kitao \& Kitao, 2002).

Some other studies in the area of reading comprehension have found that the readers adjusted their strategies and engaged themselves in a comprehension process that seemed more to suit their reading purpose. Undoubtedly, reaching a correct answer in replying to multiple-choice items in a reading text makes the test-takers select strategies to increase their chance for success and to answer the items correctly (Van Dijk, 1985; Goldman, 1997; Alderson, 2000). Some studies have focused on strategies used to answer more traditional "single selection" multiple-choice formats (i.e., basic 
comprehension and inferencing questions) versus the new selected-response (multiple selection, drag-and-drop) reading to learn items. The latter were designed to simulate the academic task of forming a comprehensive and coherent representation of a whole text, rather than focusing on discrete points in the text.

A TOEFL Monograph outlines three main perspectives for understanding the nature of reading comprehension as: the task perspective, the processing perspective, and the reader purpose perspective (Enright, Grabe, Koda, Mosenthal, Mulcahy-Ernt, \& Schedl, 2000).

Enright and Schedl (2000, p. 4) review the three perspectives, in their ETS report, namely "Reading for a Reason: Using Reader Purpose to Guide Test Design, considered the reader purpose perspective, which describes reading in terms of the coordinated application of knowledge and processes to a text or texts in the service of a goal or purpose", as representing the best model for assessment design. The reader purpose perspective identifies that the reading process is more an individual, cognitive process, what Bernhardt (as cited in Cohen \& Upton, 2007, p. 210) has called "an intrapersonal problem-solving task".

The degree of success in reading, from this perspective, functions in task characteristics as well as reader's knowledge and personal abilities. Other studies have shown that performance varied in reading comprehension. Cohen and Upton (2007) stated that the performance variation in reading comprehension occurred due to individual differences in linguistic knowledge and general and domain-specific background knowledge.

\section{Reading Strategies}

The explosion of research in second language reading has begun to focus on reading strategies. Singhal (2001, p. 1) believes that "reading strategies are of interest for the way readers manage their interaction with written text and how these strategies are related to the text comprehension". In this regard, in order to enhance comprehension, while reading, the readers attempt to make different adjustment and repair through the comprehension process. Carrell and Grabe (2002, p. 234) stated that "a reader engages in processing at the phonological, morphological, syntactic, semantic and discourse levels, as well as engages in goal setting, text-summary building, interpretive elaborating from knowledge resources, monitoring and assessment of goal achievement".

Williams and Moran (1989) stated that much of the reading process is "automatic" in nature, which is defined as reading skill upon the conscious authority. William and Moran (1989, p. 223) indicate that "the readers did exert a significant level of active control over their reading process through the use of strategies, which are conscious procedures that are deliberate and purposeful" (Williams \& Moran, 1989; Urquhart \& Weir, 1998). Other studies in this area have shown that the reading process was general, subconscious or unconscious, and more automatic, however strategies were subject to control, more intentional, and used to act upon the processes (Also see Cohen \& Upton, 2006; Cohen, 2005).

Analyzing reading strategies as a problem-solving process gives an insight as to "how readers interact with text and how their choice of strategies influences their comprehension of the text" (Cohen \& Upton, 2006, p. 2). Pressley and Afflerbach (1995) have classified reading strategies into three broad categories: (1) planning and identifying strategies which help in constructing the meaning of the text; (2) monitoring strategies which serve to regulate comprehension and learning; and (3) evaluating strategies by which readers reflect or respond in some way to the text. Various other studies in the area of second language reading have shown that second language readers drew on this same array of reading strategies (Upton \& Lee-Thompson, 2001; Carrell \& Grabe, 2002). In short, reading strategies are processes used by test-takers to enhance reading comprehension and overcome comprehension failures.

\section{RESEARCH QUESTION}

The present study aims to answer the following research question:

1. Is there any significant difference in the use of Reading strategies for different item types in a test of reading comprehension?

\section{METHOD}

\section{A. Participants}

Sixty-six respondents (26 males and 40 females) participated in the present study. They were in third year of their study in English Language and Literature at the University of Tehran. As for age range, field of study and nationality, none were the main concern of the present study.

\section{B. Instrumentation}

To achieve the purpose of the study two kinds of instruments were used in the present study. 1) A sample test of a reading comprehension of TOEFL iBT, 2) A checklist of using strategies. An account of each instrument appears in the following sections.

\section{a. Reading Comprehension Test}

The Next Generation TOEFL, a new, internet-based version of the Test of English as a Foreign Language developed by the Educational Testing Service (ETS), included both traditional (Basic comprehension) and new (Reading to Learn 
and Inferencing) item types. One section of the new test of TOEFL iBT specifically focuses on academic reading skills. Generally, reading section in the TOEFL iBT includes three passages, with thirty-nine questions. The passages are relatively lengthy (each passage is between 600 to 700 words) on academic topics.

The new TOEFL reading section uses three general item types to evaluate the reader's level of proficiency to accomplish academic reading tasks: Basic Comprehension items, Inferencing items, and Reading to Learn items (Cohen \& Upton, 2006). ETS extended for a total of ten different item types and defined five different types of Basic Comprehension items, three different types of Inferencing items, and two different types of Reading to Learn items.

Since the actual test of iBT was not available, it was decided to use the sample test of TOEFL iBT reading comprehension section (ETS, 2005). In the present study two out of three passages (22 items) of the Reading section of new TOEFL Next Generation, which contain all three general item types and specifically covered all ten different item types of TOEFL iBT were used.

\section{b. A Check-list of Strategies}

Among various questionnaires and checklists, for example, Nevo (1989), Purpura (1999), Phakiti (2003a, b), Cohen and Upton (2006), it was decided to adopt the checklist of the strategy which was used by Cohen and Upton (2006). The checklist consists of three types of strategies: Reading strategies, Test-management strategies, and Test-wiseness strategies. In this study the first part -Reading strategies (R) - was used. It is worth mentioning that the original checklist in 2006 was in paper-and-pencil format and used in the verbal report approach, while the adopted checklist in the present study was administered and programmed as computer software which was attached and performed just after the reading test.

\section{Data Analysis}

Some efforts were made in analyzing the data to bring statements in order to find out any significant difference in the use of strategies and item types. The main variable in this study, i.e., strategy and item types, were considered as nominal scales. In this case, the complexity of final results made the researcher to use statistical measures that typically run on nominal variables. The use of an appropriate statistical procedure, via probability, gives confidence to the researcher's claims that the results support the hypothesis. In this regard, this confidence would be established when an appropriate choice of statistical procedure is utilized. Non-parametric procedure is one which does not make strong assumptions about the shape of the distribution of the data (see Hatch \& Lazaraton, 1991).

The test of normal distribution upon the data revealed a skewed rather than a normal, bell-shaped distribution.

Another assumption is what non-parametric tests apply to the data that are nominal and rank-ordered (Hatch \& Lazaraton, 1991). In the present study the data was ranked ordered and the variables were nominal. As a result, this assumption also has been met with the data. In the present research aims at reaching the answer of research question, non-parametric test of Friedman was assumed as the appropriate statistical procedures. Moreover, a significance level of $0.05(p<0.05)$ was set.

\section{RESULTS AND DiSCUSSIONS}

\section{A. Reading Strategies and Item types}

In order to find a difference in using different strategies in doing reading section of TOEFL iBT, the analysis of Reading strategies with different item types will be discussed in detail in the following section. Before going through the details of analyzing each strategy via item types, a total Friedman test was conducted on Reading strategies and the item types. Results of the analysis indicated that the difference in the use of Reading strategies and item types was significant. Results show that the difference is significant $\left(\chi^{2}(9)=667.575, p=0.00\right)$. In order to confirm the results which were taken in total investigation tests, a series of Friedman tests were run for each Reading strategy. As a matter of fact, these Friedman tests were conducted with the aim of interpreting each reading strategy via item types. The results of the Friedman test are presented in Tables 1. and 2. 
TABLE 1

FRIEDMAN TEST FOR READING STRATEGIES ACROSS ITEM TYPES

\begin{tabular}{|c|c|c|c|}
\hline \multirow{29}{*}{ 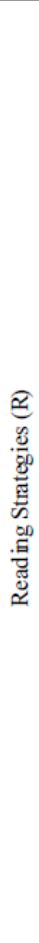 } & & $\begin{array}{l}\text { Friedman } \\
\text { Chi-square }\left(\chi^{2}\right)\end{array}$ & Asymp.sig. \\
\hline & R1 & 11.99 & 0.21 \\
\hline & $\mathrm{R} 2$ & 52.57 & 0.00 \\
\hline & R3 & 62.03 & 0.00 \\
\hline & R4 & 20.63 & 0.01 \\
\hline & R5 & 16.49 & 0.05 \\
\hline & R6 & 40.00 & 0.00 \\
\hline & R7 & 63.64 & 0.00 \\
\hline & R8 & 28.63 & 0.00 \\
\hline & R9 & 22.74 & 0.00 \\
\hline & R10 & 57.40 & 0.00 \\
\hline & R11 & 18.70 & 0.02 \\
\hline & R12 & 20.11 & 0.01 \\
\hline & R13 & 11.53 & 0.24 \\
\hline & R14 & 26.41 & 0.00 \\
\hline & R15 & 14.74 & 0.09 \\
\hline & R16 & 20.36 & 0.01 \\
\hline & R17 & 13.94 & 0.12 \\
\hline & R18 & 38.21 & 0.00 \\
\hline & R19 & 10.94 & 0.28 \\
\hline & $\mathrm{R} 20$ & 42.07 & 0.00 \\
\hline & R21 & 16.87 & 0.05 \\
\hline & R22 & 21.67 & 0.01 \\
\hline & R23 & 15.98 & 0.06 \\
\hline & R24 & 27.66 & 0.00 \\
\hline & $\mathrm{R} 25$ & 26.78 & 0.00 \\
\hline & R26 & 36.95 & 0.00 \\
\hline & R27 & 38.42 & 0.00 \\
\hline & R28 & 53.81 & 0.00 \\
\hline
\end{tabular}

TABLE 2

PERCENTAGE OF FREQUENCY FOR READING STRATEGIES ACROSS ITEM TYPES

\begin{tabular}{|c|c|c|c|c|c|c|c|c|c|c|c|}
\hline & & & & & & Item $\mathrm{Ty}$ & & & & & \\
\hline & & $B C-v$ & $B C-f$ & $\begin{array}{l}\begin{array}{c}\mathrm{BC}- \\
\mathrm{n} / \mathrm{e}\end{array} \\
\end{array}$ & BC-pr & BC-ss & I & I-it & I-1p & $\begin{array}{l}\text { R2L- } \\
\text { ps }\end{array}$ & $\begin{array}{l}\text { R2L- } \\
\text { st }\end{array}$ \\
\hline & R1 & 8.43 & 79 & 11.59 & 11.06 & 10.54 & 10.18 & 6.32 & 10.8 & 15.8 & 7.37 \\
\hline & $\overline{\mathrm{R} 3}$ & 23.82 & 10.53 & 8.86 & 6.65 & 11.63 & 7.76 & 2.77 & 8.03 & 12.19 & 7.76 \\
\hline & R4 & 7.74 & 10.69 & 12.53 & 8.11 & 9.21 & 9.34 & 7.37 & 9.21 & 18.43 & 7.37 \\
\hline & $\mathrm{R} 5$ & 9.49 & 9.28 & 7.59 & 9.7 & 8.44 & 10.97 & 8.02 & 9.49 & 16.88 & 10.13 \\
\hline & R8 & 15.21 & 12.04 & 11.4 & 8.24 & 11.4 & 10.98 & 10.14 & 9.19 & 6.34 & 5.07 \\
\hline & R9 & 10.84 & 10.06 & 9.29 & 11.61 & 7.74 & 12.9 & 10.06 & 12 & 12.39 & 3.1 \\
\hline 2 & R10 & 21.07 & 9.27 & 3.37 & 10.11 & 15.17 & 8.99 & 59 & 9.27 & 13.48 & 3.37 \\
\hline 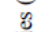 & R11 & 11.25 & 13.06 & 7.26 & 8.71 & 14.51 & 11.12 & 8.71 & 10.88 & 8.71 & 5.8 \\
\hline 80 & R12 & 8.17 & 9.57 & 11.16 & 11.56 & 8.77 & 11.69 & 7.97 & 12.76 & 11.96 & 6.38 \\
\hline 苞 & R13 & 7.53 & 10.04 & 7.03 & 10.04 & 10.54 & 11.38 & 10.04 & 10.29 & 15.06 & 8.03 \\
\hline & $\bar{R} 18$ & 14.86 & 691 & 11.06 & 11.75 & 11.75 & 12.9 & 6.91 & 10.02 & 12.44 & 1.38 \\
\hline & $\bar{R} 19$ & 9.8 & 10.78 & 12.75 & 10.29 & 10.78 & 9.8 & 4.9 & 10.29 & 9.8 & 10.78 \\
\hline & $\mathrm{R} 20$ & 7.63 & 12.85 & 11.24 & 13.25 & 9.64 & 12.85 & 6.83 & 11.24 & 11.24 & 3.21 \\
\hline & R21 & 7.59 & 11.64 & 16.19 & 9.61 & 10.62 & 10.46 & 5.06 & 9.61 & 13.15 & 6.07 \\
\hline & $\overline{\mathrm{R} 22}$ & 7.08 & 7.08 & 10.89 & 13.07 & 10.89 & 10.16 & 11.98 & 12.52 & 8.71 & 7.62 \\
\hline & $\mathrm{R} 23$ & 9.35 & 13.36 & 10.69 & 11.22 & 13.36 & 9.97 & 8.01 & 9.08 & 8.55 & 6.41 \\
\hline & R24 & 9.87 & 10.76 & 14.35 & 11.21 & 6.73 & 12.56 & 8.07 & 11.21 & 8.97 & 6.28 \\
\hline & $\overline{\mathrm{R} 25}$ & 8.19 & 9.19 & 14.38 & 8.39 & 8.39 & 13.32 & 10.39 & 10.99 & 11.19 & 5.59 \\
\hline & $\bar{R} 26$ & 10.5 & 6.77 & 10.84 & 10.84 & 17.61 & 8.58 & 10.16 & 12.53 & 6.77 & 5.42 \\
\hline & R27 & 15.5 & 10.33 & 8.86 & 11.81 & 14.76 & 8.86 & 8.86 & 9.23 & 8.86 & 2.95 \\
\hline & $\bar{R} 28$ & 21.81 & 8.85 & 8.85 & 10.12 & 10.12 & 10.54 & 6.32 & 9.48 & 7.59 & 6.32 \\
\hline
\end{tabular}

* The digits represent the percentage of weighted scores. ** (BC-v): Basic Comprehension-vocabulary,

(BC-f): Basic Comprehension - fact,

(BC-n/e): Basic Comprehension -not/except,

(BC-pr): Basic Comprehension -pronoun reference,

(BC-ss): Basic Comprehension -sentence simplification-

(I): Inferencing-basic inference,

(I-it): Inferencing-insert text,

(I-rp): Inferencing-rhetorical purpose-

(R2L-ps): Reading to Learn- prose summary,

(R2L-st): Reading to Learn- schematic table 
In the following paragraph relevant descriptive accounts of Reading strategies across different item types will be presented. The results of non-parametric test for Reading strategies revealed that there is significant difference in the use of twenty out of twenty-eight reading strategies. In other word the usage of different Reading strategies in various item types wouldn't be the same.

In detail, the result of Friedman test for strategies (R2), makes a mental note of what is learned from the pre-reading with $\left(\chi^{2}(9)=52.572, p=0.00\right)$, and R3:considering prior knowledge of the topic with $\chi^{2}(9)=62.033$, $p=0.00$ indicated that the difference is significant. For instance, R4: reads the whole passage carefully which is associated with items requiring comprehending longer texts, and connecting the detailed provided information to the whole. Reading to Learn item type, those items which need more thoughts like R2L-ps, would be the right alternative for R4. The table of percentages (see Table 2) shows that the use of R4 was mostly related to BC-f, B-.n/e, BC-ss, I, I-rp, and R2L-ps (69\%). Interestingly, as it was predicted the R2L-ps with 18.43 percent belongs the highest percentage score. In addition, the strategy rejects the null hypothesis with the significant difference $\left(\chi^{2}(9)=20.639, \mathrm{p}=0.014\right)$.

The Friedman test brought up this outcome for strategies R6 (reads a portion of the passage carefully) and R7 (reads a portion of the passage rapidly looking for specific information), which may recall those item types with targeted pronouns, facts, inferencing or rhetorical purposes, that there is a significant difference in using R6 and R7 in various item types with $\left(\chi^{2}(9)=40.009, \mathrm{p}=0.00\right)$ and $\left(\chi^{2}(9)=63.642, \mathrm{p}=0.00\right)$. Also, strategy number eight $(\mathrm{R} 8)$ looks for markers of meaning in the passage (e.g., definitions, examples, indicators of key ideas, guides to paragraph development) seems to go with Inferencing and Basic Comprehension item types. As it was mentioned by Cohen and Upton (2006), Inferencing and Basic Comprehension items required attention to textual clues, markers of cohesion, and finding factual information. Conclusively, the idea about $\mathrm{R} 8$ was supported by the percentage of frequency. It is proven that the usage of R8 mainly associated with BC-v, BC-f, BC-n/e, BC-ss, I, and I-it with 71.17\% among all item types. The statistical result also showed that there is a significant difference in the use of $R 8\left(\chi^{2}(9)=28.636, p=0.001\right)$.

Moreover, the results of non-parametric test for strategies R9 $\left(\chi^{2}(9)=22.741, p=0.007\right), \operatorname{R} 10\left(\chi^{2}(9)=57.409, p=\right.$ $0.000)$, R11 $\left(\chi^{2}(9)=18.704, p=0.028\right)$, and R12 $\left(\chi^{2}(9)=20.118, p=0.017\right)$ showed a significant difference in employing the intended strategies in various item types. In addition, strategy fourteen (during reading, monitor understanding of the passage/portion's discourse structure (e.g., compare/contrast, description, definition) discusses comprehension of an implied idea which is not expressed explicitly in the texts. Indeed, the participants are required to use their power of inferencing particularly in understanding the rhetorical purposes or in inserting the lexical, grammatical or logical links to the passage. Confirming the claim, the main use of R14 has been seen in R2L-ps and BC-n/e each with $15.97 \%$, I with $12.65 \%$ and I-rp with $11.48 \%$. Also, the Friedman test showed that there is a significant difference in using R14 for different item types $\left(\chi^{2}(9)=26.419, \mathrm{p}=0.002\right)$.

The Friedman test for the sixteenth $\left(\chi^{2}(9)=20.365, p=0.016\right)$ and the eighteenth strategy $\left(\chi^{2}(9)=38.210, p=0.000\right)$ showed a significant difference in them. Also, strategy twenty (looks for sentences that convey the main ideas) asserts that respondents should be searching for the main idea at sentence level. All item types have a sort of participation in discourse structure of questions. To confirm the claim, the highest percentage belongs to Bc.pr with $13.25 \%$, BC-f and I each with $12.85 \%$ and I-rp, R2L-ps, and BC-n/e each with $11.24 \%$ (see Table 2.) Furthermore, it is interpretable that there is a significant difference for different item types $\left(\chi^{2}(9)=42.076, \mathrm{p}=0.000\right)$. The next strategy which had significant difference $\left(\chi^{2}(9)=21.67, p=0.01\right)$ is R22. Regarding the definition of R22, it seems to be more compatible with item type BC-pr and R2L-ps. It can be justifiable that R2L-ps measures the ability of respondents to identify the main idea and relative information. The relative ideas should be taken out from each paragraph and associated in table, in order to reveal how the lines are intertwined in the paragraphs (see Table 2.). Also table 1. shows that the difference in strategies number R24, R25, R26, R27, and R28 is significant.

In order to elaborate on rejected reading strategies, ones with significant difference, and to compare them through the TOEFL item types, some Friedman tests were conducted. In order to make a comparison between different item types in any of the rejected Reading strategies, a specific statistical procedure was computed.

The following tables attempt to go through the rejected Reading strategies and aim to show the more similar item types in the intended strategies. Overall, research findings showed that sometimes some item types act more similarly or differently. Similar item types for the rejected reading strategies will be grouped in the following tables.

\section{B. Grouping Item Types for Reading Strategies}

TABLE 3

GROUPING ITEM TYPES FOR R2, R8, R9, R12, R14, R20, R25, AND R27

\begin{tabular}{|l|l|l|l|l|l|l|l|l|}
\hline \multicolumn{7}{|c|}{ R2, R8, R9, R12, R14, R20, R25, \& R27 } \\
\hline BC-v & BC-f & BC-n/e & BC-pr & BC-ss & I & I-it & I-rp & R2L-ps \\
\hline
\end{tabular}

The result shows that all ten item types acted differently in the rejected strategies number R2, R8, R9, R12, R14, R20, $\mathrm{R} 25$, and R27. It is interpretable that the performance of each item type is not much the same. 
TABLE 4

GROUPING ITEM TYPES FOR R3

\begin{tabular}{|l|l|l|l|l|l|l|l|l|}
\hline $\mathbf{R 3}$ & & BC-pr & BC-ss & I-it & I-rp & R2L-st \\
\hline BC-v & BC-f & BC-n/e & BC-pr & & I \\
\hline
\end{tabular}

It can be concluded that two item types (I \& R2L-ps) act similarly. As a matter of fact, the tendency of using R3 in the two item types is more considerable in comparison with the other item types. It is important to recognize that the ten groups of item types changed into nine. It is recognizable that if any item type has been made a group, I and R2L-ps will make one.

TABLE 5

GROUPING ITEM TYPES FOR R4

\begin{tabular}{|l|ll|l|l|l|l|l|l|}
\hline $\mathrm{R} 4$ & & & & \\
$\mathrm{BC}-\mathrm{v}$ & $\mathrm{BC}-\mathrm{f}$ & $\mathrm{I}$ & BC-n/e & BC-pr & BC-ss & I-it & I-rp \\
\hline
\end{tabular}

Table 5 shows there is little to choose between BC-f and I. It can be claimed that these two item types act more similarly toward R4.

TABLE 6

GROUPING ITEM TYPES FOR R6

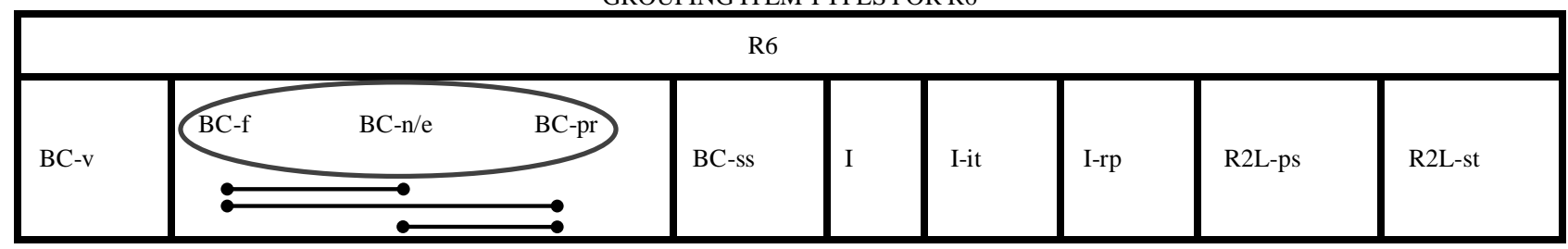

Item types BC-f with BC-n/e, BC-f with BC.pr, and BC-n/e with BC.pr have a similar interaction toward R6. In other words, BC-f, BC-n/e, and BC.pr have a rather similar performance in R6 and it is possible to set them in one group. The ten groups of item types turn into eight.

TABLE 7

GROUPING ITEM TYPES FOR R7

\begin{tabular}{|l|ll|l|l|l|l|l|l|l|l|}
\hline R7 \\
\hline BC-v & $\begin{array}{l}\text { BC-f } \\
\bullet\end{array}$ & I-rp & BC-n/e & BC-pr & BC-ss & I & I-it & R2L-ps & R2L-st \\
\hline
\end{tabular}

In R7 the BC-f and I-rp have a similar performance in strategy number seven.

TABLE8

GROUPING ITEM TYPES FOR R10

\begin{tabular}{|c|c|c|c|c|c|c|c|c|c|}
\hline \multicolumn{10}{|l|}{$\mathrm{R} 10$} \\
\hline BC-v & BC-f & BC-n/e & R2L-st & BC-pr & BC-ss & I & I-it & I-rp & R2L-ps \\
\hline
\end{tabular}

Among all item types, it is revealed that in R10 two item types, BC-n/e and R2L-st are apt to act similarly. It can be stated that BC-n/e and R2L-st are laid in one group; however, they are belonging to two different and dissimilar categories, Basic Comprehension and Reading to Learn.

TABLE 9

GROUPING ITEM TYPES FOR R11

\begin{tabular}{|lll|l|l|l|l|l|l|l|}
\hline $\mathrm{R} 11$ & & & & \\
\hline $\mathrm{BC}-\mathrm{v}$ & $\mathrm{I}$ & BC-f & BC-n/e & BC-pr & BC-ss & I-it & I-rp \\
\hline
\end{tabular}


As Table 9 shows, on one hand, item type I takes much the same action as BC-v does, and on the other hand, it has the similar interaction with Basic Comprehension-fact toward R11. It is concluded that the performance of item type I is similar to BC-v and BC-f, but not BC-v and BC-f.

TABLE 10

GROUPING ITEM TYPES FOR R16

\begin{tabular}{|l|l|l|l|l|l|l|l|l|}
\hline R16 & BC-f & BC-n/e & I & I-rp & BC-ss & I-it \\
\hline BC-v & BC-pr & BC & R2L-ps \\
\hline
\end{tabular}

TABLE 11

GROUPING ITEM TYPES FOR R18

\begin{tabular}{|l|l|l|l|l|l|l|l|l|l|}
\hline $\mathrm{R} 18$ & & & & \\
\hline BC-v & BC-pr & BC-f & BC-n/e & I & I-rp & BC-ss & I-it \\
\hline
\end{tabular}

Tables 10. and 11 can be interpreted the same. With regard to the obtained results item types BC-v and BC-pr on one hand, and I and I-rp on the other hand act more similarly in the use of R16 and R18.

TABLE 12

GROUPING ITEM TYPES FOR R22

\begin{tabular}{|c|c|c|c|c|c|c|c|c|c|}
\hline R22 & & & & & & & & & \\
\hline BC-v & BC-n/e & BC-f & BC-pr & BC-ss & I-rp & I & I-it & R2L-ps & R2L-st \\
\hline
\end{tabular}

The Friedman test revealed that there is significant difference in the use of R22 for item types. But which item type exactly? Results in Table 12 show that four item types, BC-v, BC-n/e, BC-ss, and I-rp perform similarly in R22. Considering the results, BC-v and BC-n/e act similarly while, BC-ss and I-rp do the same. In this case, four item types are put in two different groups and ten groups are turned into eight.

TABLE 13

GROUPING ITEM TYPES FOR R24

\begin{tabular}{|l|l|l|l|l|l|l|l|l|l|}
\hline R24 & & & & & \\
\hline BC-v & BC-ss & BC-f & BC-n/e & BC-pr & I & I-it & I-rp & R2L-ps \\
\hline
\end{tabular}

The same interpretation would be extended about reading strategy number twenty four. The two item types BC-v and BC-ss, in R24 act as being two of a kind and get involved in the same group. Whereas, other remaining item types acted differently in R24.

TABLE 14

GROUPING ITEM TYPES FOR R26

\begin{tabular}{|l|l|l|ll|l|l|l|l|l|}
\hline R26 & BC-f & BC-n/e & BC-pr & I-rp & BC-ss & I & I-it \\
\hline BC-v & BC-f & & & & R2L-ps \\
\hline
\end{tabular}

On one hand, BC-pr and I-rp, and on the other R2L-ps and R2L-st have a similar performance in R26. A pertinent point to note; in essence, strategy number 26 (verifies the referent of a pronoun) as it was discussed before, goes with BC-pr. While the remarkable result revealed that BC-pr and I-rp act similarly in R26.

TABLE 15

GROUPING ITEM TYPES FOR R28

\begin{tabular}{|c|c|c|c|c|c|c|c|c|c|}
\hline R28 & & & & & & & & & \\
\hline BC-V & $B C-f$ & BC-pr & BC-n/e & BC-ss & I & I-it & R2L-ps & I-rp & R2L-st \\
\hline
\end{tabular}


As Table 15 informs, BC-f and BC-pr in one way and I-it and R2L-ps in other way act similarly and form groups of two.

From the above findings of research in Reading strategies, it becomes clear that all the item types were employed in the rejected reading strategies but some of them acted more similarly in the specific strategy.

\section{CONCLUSIONS AND SUGGESTIONS FOR FURTHER RESEARCH}

The present study investigated differences in test-taking strategies use in the reading test context. It has provided empirical evidence that employing Reading strategies play a significant role in the test of reading comprehension of TOEFL iBT.

\section{A. Limitations and Delimitations}

a. The test administered to the participants of this study was a low-stakes test task as their score did not have any sort of impact on their educational profile. In that case, for the test-takers the conditions were different from those in place when they actually take the TOEFL test.

b. No distinction was made between strategies used for test items that were answered accurately contrary to those answered inaccurately. Considering this variable might provide us with a clearer picture concerning the test takers' effectiveness of their strategy use.

c. The participants were Iranian junior students at the B.A level. All the participants in the present study have had the same first linguistic background. Using the same approaches in the present study is quite promising area to the students with different first linguistic background.

d. The checklist in the present study was adopted from Cohen and Upton (2006) which was more suitable for think aloud procedures in the reading comprehension test of TOEFL iBT. But it was ignored because of time related constraints.

\section{B. Suggestions for Further Research}

Due to the cyclical nature of any research more questions tend to be raised than are answered. In the established tradition of scientific inquiry this section offers several suggestions for future researchers to utilize in investigating the different areas.

a. This study analyzed test-taking strategies in the reading section of TOEFL iBT. The same procedure can be replicated in analyzing other skills of language writing (Cumming et al., 2000), speaking (Butler et al., 2000), and listening (Douglas et al., 2000).

b. To make the research manageable, this study investigated reading strategies through the checklist of strategies. The same procedure can be practiced through protocol analysis and verbal reports, specifically, think-aloud (Cohen \& Upton, 2006).

c. The sample size of this research was $66 \mathrm{EFL}$, a low-stakes research. A high-stakes community in a larger size might be deployed to analyze and test the research questions of study.

d. Another way of extending the present research would be an idea of construct validity and item analysis (Anderson, et al., 1991; Alavi, 2005). This area is quite a promising area to be probed by Iranian researchers.

e. Furthermore, variables of age and field of study are quite promising areas and could be investigated. But, in the present study the age and field of study were ignored because of the time related constrains and study constrictions.

f. All the participants in the present study have had the same first language background knowledge. Another way to conduct the present research may be considered in the light of sociolinguistics. The same approaches in the present study probably applicable to other students with a different first language, such as Turkish, Armenian, and Hebrew in Iran may be carried out. This would be an attempt to explain how test-takers use their sources of language especially using L1 in their verbal report (Nevo, 1989).

\section{Conclusions}

The underlying goal of this study was to gain a better understanding of how Reading strategies are used by test-takers in the reading section of TOEFL iBT (Cohen \& Upton, 2006; Phakiti, 2003a, b; Purpura, 1997, 1999). The focus was on the strategies that the participants (26 male and 40 females) used in producing answers of the reading comprehension of iBT. The basic assumption being made in this study is that the number of Reading strategies which participants used in taking test is different in ten item types of reading section. To summarize the findings of this study in terms of research question, the results did not confirm hypothesis, which predicted that using Reading strategies would not be different in various item types of reading section of TOEFL iBT. In terms of item types, it is found that strategies number R2, R8, R9, R12, R14, R20, R25, and R27 to be treated differently in the Reading strategies. Whereas, the use of strategies number R3, R4, R6, R7, R10, R11, R16, R18, R22, R24, R26, and R28 was similar in doing item types. In this vein, this study, suggests a need for more research into different learning potentials and test-taking skills stimulated by various using strategies.

\section{REFERENCES}


[1] Aebersold, J. \& Field, M. (1997). From reader to reading teacher: issue and strategies for second language classrooms. Cambridge: Cambridge University press.

[2] Alavi, S. M. (2005).On the adequacy of verbal reports in examining an underlying construct of a test. Studies in Educational Evaluation, 31, 1-26.

[3] Alderson, J. c. (2000). Assessing reading. Cambridge: Cambridge University Press.

[4] Anderson, N. J., Bachman, L., Perkins, K., \& Cohen, A. (1991). An exploratory study into the construct validity of a reading comprehension test: Triangulation of data sources. Language Testing, 8(1), 41-66.

[5] Anderson, R. \& Pearson, P. (1984). A schema-theoretic view of basic processes in reading comprehension. In Pearson, P.D., Editor, Handbook of reading research. New York: Longman, 255-91.

[6] Bachman, L. F. (2000). Modern language testing at the turn of the century: Assuring that what we count counts. Language Testing, 17 (1) 1-42.

[7] Barnett, M. (1989). More than meets the eye: foreign language reading theory and practice. Englewood Cliffs. NJ: CAL and Prentice-Hall.

[8] Birch, B. (2002). English L2 reading: getting to the bottom. Mahwah, NJ: Erlbaum.

[9] Butler, F.A., Eignor, D., Jones, S., McNamara, T., \& Suomi, B.K. (2000). TOEFL® Monograph No. MS-20.

[10] Canale, M., \& Swain, M. (1980). Theoretical bases of communicative approaches to second language teaching and testing. Applied Linguistics, 1(1), 1-47.

[11] Carrell, P. (1984), Schema theory and ESL reading: classroom implications and applications. The Modern Language Journal, $68,332-43$.

[12] Carrell, P. L., \& Grabe, W. (2002). Reading. In N. Schmitt (Ed.), An introduction to applied linguistics (pp. 233-250). London: Arnold.

[13] Clarke, A. (1979). Reading in Spanish and English. Language Learning, 29, 121-50.

[14] Cohen, A. D. (1980). Testing language ability in the classroom. Rowley, M.A: Newbury House Publishers.

[15] Cohen, A. D. (1994). Assessing language ability in the classroom (2nd ed.). Boston: Newbury House/Heinle \& Heinle.

[16] Cohen, A. D. (2005, June). Coming to terms with language learner strategies: What do strategy experts think about the terminology and where would they direct their research? Paper presented at the 2nd International Conference of the Centre for Research in International Education, AIS St. Helens, Auckland, NZ.

[17] Cohen, A., \& Upton, T. (2006). Strategies in responding to the new TOEFL reading tasks. Monograph Series: ETS.

[18] Cohen, A. D. \& Upton, T. A. (2007). "I want to go back to the text": Response strategies on the reading subtest of the New TOEFL. Language Testing, 24(2), 209-250.

[19] Cumming, A., Kantor, R., Powers, D., Santos, T., \& Taylor, C. (2000). TOEFL® Monograph No. MS-18.

[20] Douglas, D. and Smith, J. (1997). Theoretical underpinnings of the Test of Spoken English revision project (TOEFL Monograph Series No. 9). Princeton, NJ: Educational Testing Service.

[21] Enright, M.K., Grabe, W., Koda, K., Mosenthal, P., Mulcahy-Ernt, P. and Schedl, M. (2000). TOEFL 2000 reading framework: A working paper Andrew D. Cohen and Thomas A. Upton 245 (TOEFL Monograph Series Report No. 17). Princeton, NJ: Educational Testing Service.

[22] Enright, M.K. and Schedl, M. (2000). Reading for a reason: Using reader purpose to guide test design (A Draft TOEFL 2000 Report). Princeton, NJ: Educational Testing Service.

[23] ETS, (2005). TOEFL iBT sample questions. www.ets.org/toefl. Educational Testing Service.

[24] Fountas, I and Pinnell, G. (1999). Matching books to readers: Using leveled books in guided reading, K-3. New York: Heinemann.

[25] Goldman, S. R. (1997). Learning from text: Reflections on the past and suggestions for the future. Discourse Processes, 23 , 357-98.

[26] Grabe, W. (2000). Developments in reading research and their research and their implication for computer-adaptive reading assessment. In Chalhoub-deville, M., (Ed.), Issues in computer-adaptive tests of reading, Mahwah, NJ: Erlbaum, 249-67.

[27] Hatch, E., \& Lazaraton, A. (1991). A research manual: Design and statistics for applied linguistics. NY: Newbury House Publishers.

[28] Kitao, S. K. \& Kitao, K. (2002). Testing reading. Asian Journal of English Language Teaching. 12, 161-78.

[29] Klein-Braley, C. (1981). Empirical investigation of cloze tests: An examination of the validity of cloze tests as tests of general language proficiency in English for German university students. Unpublished doctoral dissertation. Duisburg, West Germany: University of Disburg.

[30] Lin, J. \& Wu, F. (2004). Differential performance by gender in foreign language testing. Paper presented at the annual meeting of the national council on measurement in education (Chicago, IL.).

[31] McDonough, S. H. (1995). Strategy and skill in learning a foreign language. London. Hodding Headline PLC.

[32] MacDonough, S. H. (1999). Learner strategies. Language Teaching. 32, 1-18.

[33] Messick, S. A. (1989). Validity. In Linn, R. L., Editor, Educational measurement, (3 ${ }^{\text {rd }}$ edition). New York: American Council on Education/ Macmillan Publishing Company.

[34] Nevo, N. (1989). Test-taking strategies on a multiple choice test of reading comprehension. Language Testing, 6(2), $199-215$.

[35] Nitko, A.J. (1983). Educational tests and measurement: an introduction. New York: Harcourt Brace Jovanovich.

[36] Nunan, D. (1999). Second language teaching and learning. Boston, M.A: Heinle \& Heinle.

[37] Oxford, R. L. (2003). Language learning styles and strategies: An overview. Learning Styles \& Strategies, Oxford, GALA.

[38] Phakiti, A. (2003a). A closer look at the relationship of cognitive and metacognitive strategy use to EFL reading achievement test performance. Language Testing, 20(1), 26-56.

[39] Phakiti, A. (2003b). A closer look at gender and strategy use in L2 reading. Language Learning, 53(4), 649-702.

[40] Pressley, M. \& Afflerbach, P. (1995). Verbal protocols of reading: The nature of constructively responsive reading. Hillsdale, NJ: Lawrence Erlbaum. 246 Reading subtest of the new TOEFL 
[41] Purpura, J. (1997). An analysis of the relationships between, test takers' cognitive and metacognitive strategy use and second language test performance. Language Learning, 47 (2), 289-325.

[42] Purpura, J. E. (1999). Learner strategy use and performance on language tests: A structural equation modeling approach.

[43] Rumelhart, D. (1980). Schemata: the building blocks of cognition. In Spiro, R. J., Bruce, B. C. and Brewer, B. W., (Eds.) Theoretical issues in reading comprehension. Hillsdale, NJ: Erlbaum, 33-58.

[44] Rupp, A. A., Ferne. T., Choi. H. (2006). How assessing reading comprehension with multiple-choice questions shapes the construct: a cognitive processing perspective. Language Testing. 23 (4), 441-474.

[45] Segel, K. W. (1986). Does a standardized reading comprehension test predict textbook prose reading proficiency of a linguistically heterogeneous college population? Unpublished $\mathrm{PhD}$ dissertation, The University of Texas at Austin.

[46] Singhal, M. (2001). Reading proficiency, reading strategies, metacognitive awareness and L2 readers. The Reading Matrix 1 (1), p. 1.

[47] Stanovich, K. (1980). Toward an interactive- compensatory model of individual differences in the development of reading fluency. Reading Research Quarterly, 16, 32-71.

[48] Tyner, B. (2004). Small group reading instruction. Deleware: International Reading Association.

[49] Upton, T.A. and Lee-Thompson, Li-Chun. (2001). The role of the first language in second language reading. Studies in Second Language Acquisition 23(4), 469-95.

[50] Uruquhart, S., \& Weir, C. (1998). Reading in a second language: Process, product and practice. Harlow, Essex, England: Longman.

[51] Van Dijk, T. (1985). Strategic discourse comprehension. In Ballmer, T., (Ed.) Linguistic dynamics: Discourses, procedures, and evolution. Berlin: Walter de Gruyter, 36-61.

[52] Wenden, A. L. (1987). Incorporating learner training in the classroom. In Wenden \& Rubin. (1987). Learner strategies in language learning. London: Prentice Hall International (pp. 159-68).

[53] Wenden, A. \& Rubin, J. (Eds.). (1987). Learner strategies in language learning. London: Prentice Hall International.

[54] Williams, E., \& Moran, C. (1989). Reading in a foreign language at intermediate and advanced levels with particular reference to English. Language Teaching, 22(4), 217-228.

[55] Young, D. and Oxford, R. (1997). A gender-related analysis of strategies used to process input in the native language and a foreign language. Applied Language Learning 8, 43-73.

[56] Zhi-hong, CAO. (2007, April). The effect of Learning strategies on reading comprehension. Sino-US English Teaching, Vol. 4, No. 4, (Serial No. 40, pp. 180-198).

[57] Zimmerman, B. J. (2004). Sociocultural influence and students' development of academic self-regulation. A social cognitive perspective. In D. M. McInerney, \& S. Van Etten (Eds.), Research on sociocultural influences on motivation and learning: Big theories revisited (Vol. 4, pp.139-164). United States of America.

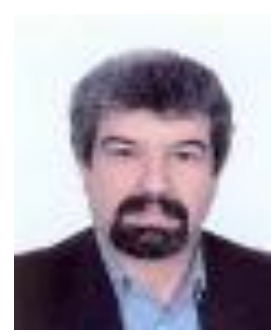

Sayyed Mohammad Alavi is an associate professor of Applied Linguistics in the Department of English Language and Literature. He teaches language testing and assessment, teaching methodology, and ESP to BA, $\mathrm{MA}$, and PhD students. He is the head of Language Testing Centre of University of Tehran, where he develops and administers the University of Tehran English Language Proficiency Test (UTEPT). Currently, he is the Vice Dean of Educational Affairs of Faculty of Foreign Languages and Literatures. He is also the committee member of TELLSI (Teachers of English Language and Literature Society of Iran). His main areas of research are in language testing and assessment, ESP, and Task Based Language Teaching.

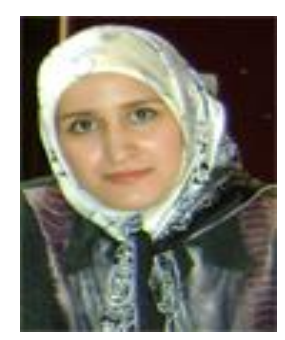

Soodeh Bordbar finished her MA in Teaching English as a Foreign Language (TEFL) in University of Tehran (UT), in 2009. She taught general English and TOEFL and IELTS preparation courses in International University of Chabahar. She also developed ESP tests for MBA courses. Currently she is a lecturer at the UT. She is a program advisor to some private English language institutes in Tehran and runs teacher training courses in these institutes. Her main research interests are Language Testing, and Task Based Language Teaching. She is a member of an international society of British Association of Applied Linguistics (BAAL). She presented papers in BAAL's annual conferences in 2010 and 2011. 